\title{
Tubulocystic Carcinoma of the Kidney, a Rare Distinct Entity
}

\author{
Shreenath Bishu, Laurie J. Eisengart and Ximing J. Yang* \\ Department of Pathology, Northwestern University, \\ Feinberg School of Medicine, Feinberg, Chicago, IL
}

USA

\section{Introduction}

Tubulocystic carcinoma is a rare renal tumor with distinct characteristics which were recently described in details in three large series $(1,2,3)$. Tubulocystic carcinomas of the kidney well circumscribed tumors. They are usually solitary and are composed of closely packed tubules and cysts separated by fibrous stroma and lined by a single layer of cuboidal cells with eosinophilic cytoplasm and prominent nucleoli, sometimes with a hobnail appearance. These tumors show a low but definite risk of metastasis, and it is therefore important to distinguish them from other benign and malignant renal lesions included in the differential diagnosis.

Tubulocystic carcinoma was originally described as a subtype of collecting duct carcinoma (4). Carcinoma of the collecting duct of Bellini, first described by Pierre Masson (5) and characterized by a tubular or tubulopapillary growth pattern with high grade nuclei, follows an aggressive clinical course with a very poor prognosis. When tubulocystic carcinoma was first described, it was included in a series of 13 cases called "low grade collecting duct carcinoma" (4); these tumors feature a favorable clinical outcome distinct from high grade collecting duct carcinoma of the kidney. The entity "low grade collecting duct carcinoma" was later divided into two distinct subtypes, mucinous tubular and spindle cell carcinoma (6-8) and tubulocystic carcinoma (5). While mucinous tubular and spindle cell carcinoma is now recognized as a distinct subtype of renal cell carcinoma (RCC) in the World Health Organization classification system of renal tumors (WHO) (3), tubulocystic carcinoma is still being characterized $(1,2,3,9)$ and is not yet included in the current WHO classification system. Mounting morphologic, biologic, immunohistochemical, and molecular evidence supports that this tumor represents a unique subtype of $\operatorname{RCC}(1,2,3)$.

\section{Clinical presentation and epidemiology}

In the majority of cases, the tumor is discovered incidentally. Less commonly, a patient with tubulocystic carcinoma of the kidney may present with nonspecific abdominal pain, a flank mass, distention, gross hematuria or unintentional weight loss as in reported cases $(1,4,9)$.

\footnotetext{
${ }^{*}$ Correspondig Author
} 
Tubulocystic carcinoma occurs in the $4^{\text {th }}$ through the $9^{\text {th }}$ decades of life. Patients range in age from 30 to 80 years in the 64 reported cases $(1,2,3,9)$, with an overall mean age of 57.2 years. Tubulocystic carcinoma arises in men in the vast majority of cases, with an overall male to female ratio of $7: 1$.

\section{Gross pathology}

Tubulocystic carcinomas are well circumscribed masses composed of multilocular cystic spaces, some containing serous fluid. The cut surface is characteristically described as "bubble-wrap", "spongy" or "Swiss cheese" in appearance due to the multiple cystic spaces. The tumors typically do not show areas of solid growth, and hemorrhage or necrosis is uncommon. The reported sizes of these tumors have ranged from 0.5 to $17.5 \mathrm{~cm}$ with an overall mean of $4.3 \mathrm{~cm}$. The majority of the tumors involve the renal cortex or the cortex and medulla $(1,2,3,9)$, not the medulla alone, which would be the typical location of a collecting duct carcinoma.

In the majority of recently studied cases (51 of 64), tubulocystic carcinoma arises as a single nodule. Yang et al. reported 5 of 13 cases were associated with papillary renal cell neoplasms.

\section{Histology}

The tumors are composed of variably sized, closely packed tubules and cysts separated by thin fibrous septae. There is no ovarian-type stroma or desmoplasia in the fibrous septae. The cysts typically range from 0.05 to $2 \mathrm{~mm}$, but can be as large as $1 \mathrm{~cm}(1,3)$. Areas of papillary architecture or solid growth are not identified unless the tumor is associated with papillary cell neoplasms. The tubules and cysts are lined by a single layer of cuboidal cells with eosinophilic cytoplasm (Figure 1). A hobnail morphology is characteristic. Nucleoli are typically prominent, and the majority of cases would be graded as Fuhrman nuclear grade 3. Although we typically do not grade tubulocystic carcinoma with Fuhrman grading system since this tumor is biologically low grade. Mitoses are rare or absent. Necrosis or lymphovascular invasion is usually not identified.

One of the common findings associated with tubulocystic carcinoma is the coexisting papillary renal cell neoplasms. In the previous study, tubulocystic carcinoma was found adjacent to and/or intermingled with papillary renal cell carcinoma (RCC) and papillary adenoma in 4 of 15 cases, and 1 was found in conjunction with papillary carcinomatosis (3). The associated papillary RCC can be type 1 or type 2 (Figure 2). The findings have been substantiated with more cases in our experience although other series have not reported tubulocystic carcinoma in association with other forms of $\operatorname{RCC}(1,2,4,9)$.

\section{Differntial diagnosis}

The differential diagnosis includes simple cortical cyst, cystic nephroma, multilocular cystic RCC, and mixed epithelial and stromal tumor of the kidney.

Simple cortical cysts

Simple cortical cysts are not multilocular, and the lining cells resemble normal renal tubules. 


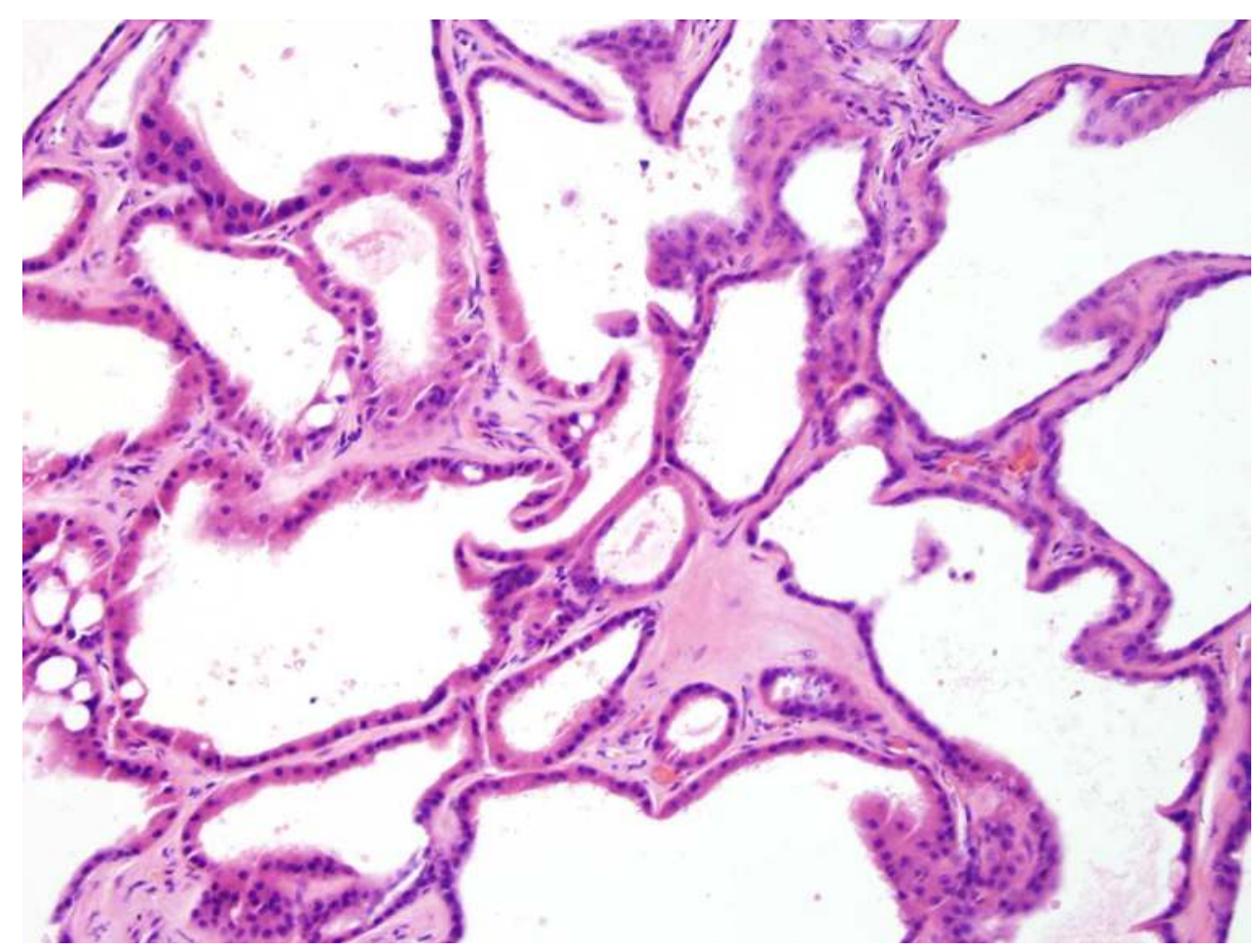

Fig. 1. Tubulocystic carcinoma is composed of cystic structures lined by tumor cells with eosinophilic cytoplasm and prominent nucleoli.

\section{Cystic nephroma}

Cystic nephroma can be multiloculated and lined by a single layer of epithelial cells. The lining epithelium is composed of flattened or attenuated cells; there may be hobnailing. However, significant nuclear atypia is absent and nucleoli are not prominent. Also cystic nephroma may have ovarian-type of stroma.

Mixed epithelial and stromal tumor

Mixed epithelial and stromal tumor of the kidney can be distinguished by the presence of stromal proliferation in the septae and variable histology of the cyst lining cells, which are typically not high nuclear grade.

Multilocular cystic renal cell carcinoma

The cysts of multilocular cystic RCC are lined by clear cells similar to clear cell RCC, without eosinophilic cytoplasm or high nuclear grade; nests of clear cells are also present in the walls of the cysts.

\section{Immunohistochemistry}

Tubulocystic carcinoma is positive for CD10 and AMACR (P504S), and shows weak or heterogeneous staining for CK7 $(2,10)$. Strong staining is seen for CK8, CK18 and CK19 $(1,2$, 
9). It is also positive for Pax2, kidney specific cadherin, carbonic anhydrase IX, and parvalbumin (1). There have been mixed reports of the expression of high molecular weight cytokeratin and UEA-1 (1, 2, 9, 11). This mixture of expression of proximal and distal nephron markers argues against origin from the collecting duct system. Yang et al. have proposed that the AMACR and CK7 expression, along with other features (see Gross Pathology and Molecular Characteristics) suggests a relationship with papillary RCC.

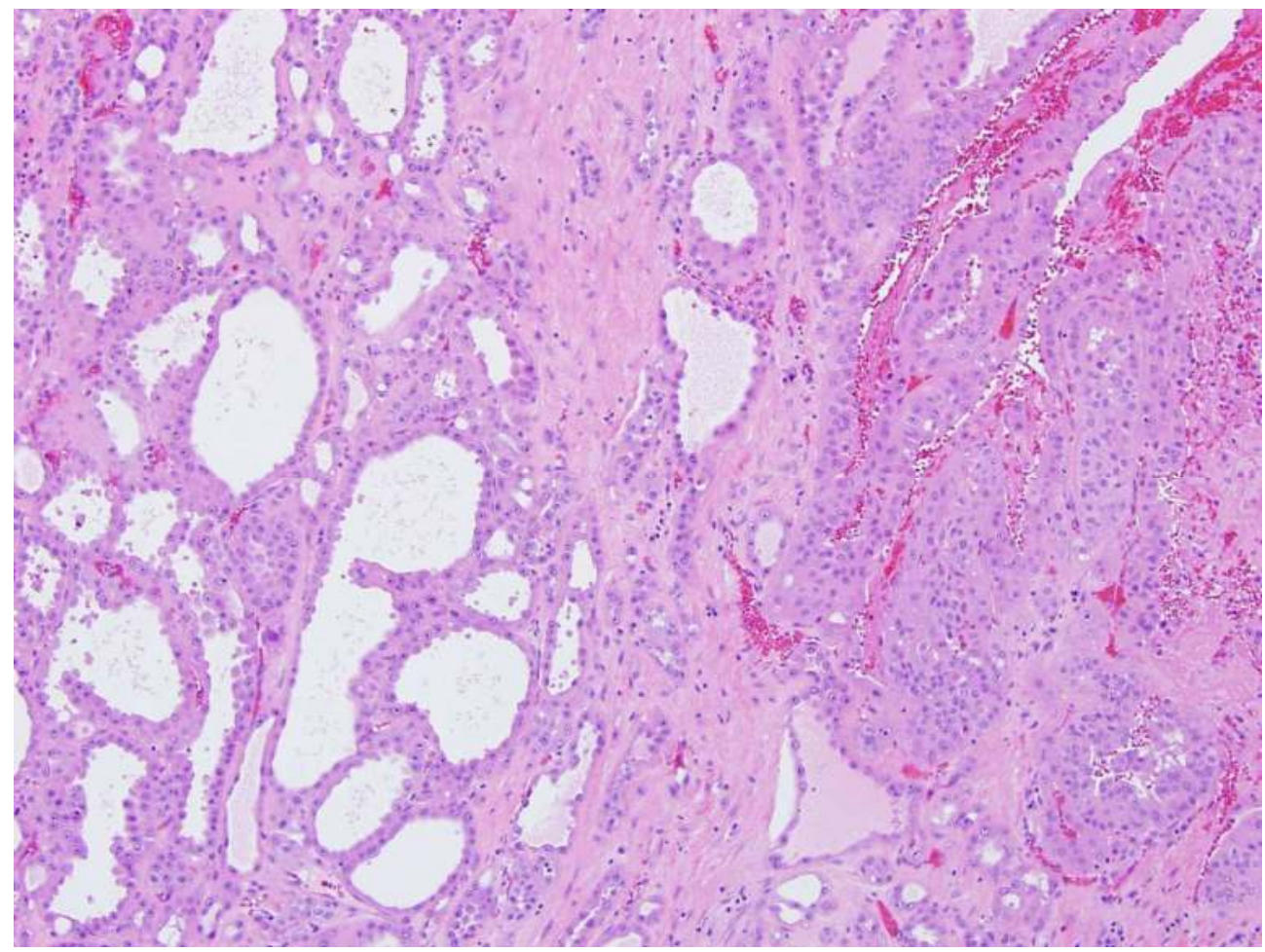

Fig. 2. Co-existing tubulocystic carcinoma (on the left side) and type 2 papillary RCC, high grade (on the right side) of the photo.

\section{Ultrastructural features}

Amin et al. report that electron microscopy of tubulocystic carcinoma reveals features of both proximal convoluted tubules and intercalated cells of the collecting duct (1). Abundant microvilli with brush border organization was reminiscent of proximal convoluted tubules. A few cells showed shorter, sparse microvilli with cytoplasmic interdigitation, corresponding to intercalated cells. Mitochondria are abundant in tumor cells $(1,9)$.

\section{Molecular features}

Yang et al. demonstrated a unique molecular signature of tubulocystic carcinoma in comparison to other renal tumors $(n=55)$ and normal renal tissue using gene expression 
microarray analysis. Clustering analysis of that data revealed tubulocystic carcinoma to be closely related to papillary RCC; both types 1 and 2 dimensional clustering placed tubulocystic carcinoma between low and high grade papillary RCC. Comparative genomic microarray analysis was performed and demonstrated gains of chromosome 17p and 17q (trisomy 17), similar to papillary RCC. Gains of chromosome 7p and 7q (trisomy 7), also characteristic of papillary RCC, were not identified in the one case of tubulocystic carcinoma studied (3).

A recent study by Zhou et al on tubulocystic carcinoma and papillary RCC was performed by multicolor fluorescence in situ hybridization (FISH) assay containing probes for chromosomes 7, 17, and Y. Typically papillary RCCs have frequent loss of chromosome $\mathrm{Y}$, and gains of chromosomes 7 and 17 (trisomies 7 and 17). Particularly chromosome 17 gain is believed to be relatively specific for papillary RCC, as previously reported in $93 \%$ to $100 \%$ of papillary RCC (12). This study by Zhou et al showed that 10/12 (83\%) cases of tubulocystic carcinoma had chromosome 7 gains, while only 8/12 (66.7\%) cases had chromosome 17 gains, and 8/9 cases had the $\mathrm{Y}$ chromosome loss. The findings suggested a strong genetic similarity between tubulocytic carcinoma and papillary RCC. However, they are not identical in the cytogenetic changes, since one third of tubulocytic carcinomas cases did not demonstrated typical gains of chromosome 17, which are relatively specific for papillary RCC.

Using gene expression profiling, Amin et al. found differential expression of genes related to cell cycle and biomolecule metabolism when compared to clear cell and chromophobe RCCthe origin from the collecting duct of Bellini. However, the findings suggest that tubulocytic carcinoma is a distinct subtype of renal cell carcinoma, no papillary RCCs were included in the comparison (1).

Recently, Osunkoya et al.compared mRNA expression of several genes in tubulocystic and collecting duct carcinomas. The genes were chosen in light of immunohistochemical characterization of these tumors (see Immunohistochemistry). Tubulocystic carcinomas showed relative overexpression of vimentin, p53 and AMACR. While not statistically significant, tubulocystic carcinoma tended to have higher levels of E-cadherin and CD10, and lower levels of CK19. CK7 and parvalbumin expression were not different between the two groups 13).

\section{Clinical outcome and prognosis}

The majority of tumors $(50 / 64)$ have been stage T1 at presentation; 9 were stage T2 and 5 were $\mathrm{T} 3(1,2,3,9,11)$. Where tumors were discovered antemortem, treatment was with total or partial nephrectomy $(1,2,3,911)$.

Where available, clinical follow-up has ranged from 3 to104 months. The vast majority of patients did not experience recurrence or metastasis, and were alive with no evidence of disease. MacLennan et al. report one patient who died of widespread intraabdominal metastasis 46 months after diagnosis (11). Yang et al. reported one patient with pelvic lymph node metastasis at nephrectomy that the metastatic tumor was histologically identical to the primary, but no evidence of disease with limited follow-up (3). Other patients in that series did show metastatic disease from their concurrent papillary RCC. In the series by Amin et al, one patient developed local recurrence and two developed distant metastasis, one to liver and both to bone (1). All the patients in the series by Azoulay et al. had no evidence of recurrence or metastasis (2).

Overall, tubulocystic carcinomas have a small but definite risk for metastasis, and are best considered a low malignant tumor. This risk is markedly increased when tubulocystic carcinoma is associated with high grade papillary RCC. 


\section{Conclusion}

Tubulocystic carcinoma is a rare renal tumor with distinct characteristics. Although originally described as a low grade collecting duct carcinoma, the biologic behavior, immunohistochemical profile, and molecular signature of these tumors do not support origin from the collecting ducts of Bellini, and suggests that they are a distinct subtype of renal cell carcinoma, with a close relationship to papillary renal cell carcinoma. This relationship has been observed in a subset of tubulocystic carcinoma and needs further investigation. These tumors show a low but definite risk of metastasis, and it is therefore important to distinguish them from other renal lesions in the differential diagnosis.

\section{References}

[1] Amin MB, MacLennan GT, Gupta R, et al. Tubulocystic carcinoma of the kidney: clinicopathologic analysis of 31 cases of a distinctive rare subtype of renal cell carcinoma. Am J Surg Pathol. 2009;33:384-392.

[2] Azoulay S, Vieillefond A, Paraf F, et al. Tubulocystic carcinoma of the kidney: a new entity among renal tumors. Virchows Arch. 2007;451:905-909.

[3] Yang XJ, Zhou M, Hes O, et al. Tubulocystic carcinoma of the kidney: clinicopathologic and molecular characterization. Am J Surg Pathol. 2008;32:177-187.

[4] MacLennan GT, Farrow GM, Bostwick DG. Low-grade collecting duct carcinoma of the kidney: report of 13 cases of low-grade mucinous tubulocystic renal carcinoma of possible collecting duct origin. Urology. 1997;50:679-684.

[5] Masson P. Tumeurs Humaines 1955. Human Tumors, Histology, Diagnosis and Technique. Detroit: Wayne State University Press; 1970.

[6] Parwani AV, Husain AN, Epstein JI, et al. Low-grade myxoid renal epithelial neoplasms with distal nephron differentiation. Hum Pathol. 2001;32:506-512.

[7] Srigley JR, Eble JN, Grignon DJ. Unusual renal cell carcinoma (RCC) with prominent spindle cell change possibly related to the loop of Henle. Modern Pathology. 1999;12:107A.

[8] Srigley JR, Kapusta L, Reuter V. Phenotypic, molecular, and ultrastructural studies of a novel low grade renal epithelial neoplasm possibly related to the loop of Henle. Modern Pathology. 2002;15:182A.

[9] Farah R, Ben-Izhak O, Munichor M, et al. Low-grade renal collecting duct carcinoma. A case report with histochemical, immunohistochemical, and ultrastructural study. Ann Diagn Pathol. 2005;9:46-48.

[10] Eble JN SG, Epstein JI. Pathology and Genetics of Tumors of the Urinary System and Male Genital Organs. Lyon: IARC Press; 2004.

[11] MacLennan GT, Bostwick DG. Tubulocystic carcinoma, mucinous tubular and spindle cell carcinoma, and other recently described rare renal tumors. Clin Lab Med. 2005;25:393-416.

[12] Zhou M, Yang XJ, Lopez J. Renal tubulocystic carcinoma is closely related to papillary renal cell carcinoma: implications for pathologic classification. Am J Surg Pathol. 2009.

[13] Osunkoya AO, Young AN, Wang W, et al. Comparison of Gene Expression Profiles in Tubulocystic Carcinoma and Collecting Duct Carcinoma of the Kidney. Am J Surg Pathol. 2009. 


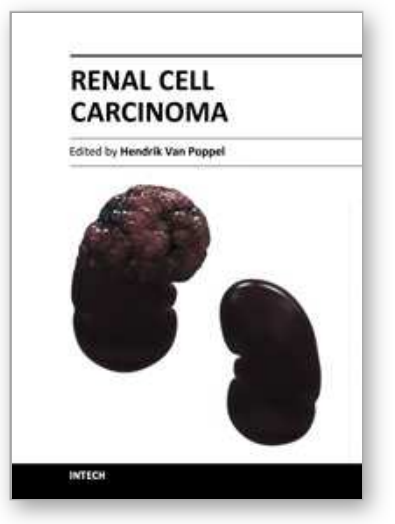

\author{
Renal Cell Carcinoma \\ Edited by Dr. Hendrik Van Poppel
}

ISBN 978-953-307-844-1

Hard cover, 144 pages

Publisher InTech

Published online 16, December, 2011

Published in print edition December, 2011

Surgical and medical oncologists have been unable to decrease renal cell carcinoma mortality for uncertain reasons, although a lot of progress has been made in diagnosis and imaging, recognition of different genetic and pathological entities, management of localized disease and in the research on new drug treatments for advanced stages of the disease, potentially combined with surgery. The purpose of this book, which tackles a number of separate interesting topics, is to provide further insight into the disease and the management of early and advanced renal cell carcinoma. The volume is divided into different parts; the first part covers the characterization of renal masses and the second part covers rare distinct pathological entity. In the management section, active surveillance, partial nephrectomy and radiofrequency ablation are presented. A separate chapter reviews the management of Von Hippel Lindau disease, and finally, conventional and aberrant signaling pathways are explored.

\title{
How to reference
}

In order to correctly reference this scholarly work, feel free to copy and paste the following:

Shreenath Bishu, Laurie J. Eisengart and Ximing J. Yang (2011). Tubulocystic Carcinoma of the Kidney, a Rare Distinct Entity, Renal Cell Carcinoma, Dr. Hendrik Van Poppel (Ed.), ISBN: 978-953-307-844-1, InTech, Available from: http://www.intechopen.com/books/renal-cell-carcinoma/tubulocystic-carcinoma-of-the-kidney-arare-distinct-entity

\section{INTECH}

open science | open minds

\section{InTech Europe}

University Campus STeP Ri

Slavka Krautzeka 83/A

51000 Rijeka, Croatia

Phone: +385 (51) 770447

Fax: +385 (51) 686166

www.intechopen.com

\section{InTech China}

Unit 405, Office Block, Hotel Equatorial Shanghai

No.65, Yan An Road (West), Shanghai, 200040, China 中国上海市延安西路65号上海国际贵都大饭店办公楼 405 单元 Phone: +86-21-62489820

Fax: $+86-21-62489821$ 
(C) 2011 The Author(s). Licensee IntechOpen. This is an open access article distributed under the terms of the Creative Commons Attribution 3.0 License, which permits unrestricted use, distribution, and reproduction in any medium, provided the original work is properly cited. 